\title{
Myocardial Performance Index
}

National Cancer Institute

\section{Source}

National Cancer Institute. Myocardial Performance Index. NCI Thesaurus. Code C139043.

A calculated result that uses the following formula to quantify both systolic and diastolic ventricular function: $\mathrm{MPI}=$ IVCT + IVRT ) / VET, in which IVCT is isovolumetric contraction time, IVRT is isovolumetric relaxation time, and V ET is ventricular ejection time. 